\title{
CSSR2019
}

6th International Conference on Science \& Social Research 2019

https://cssr.uitm.edu.my/2019/

Parkroyal Penang Resort, Batu Ferringhi, Pulau Pinang, Malaysia, 04-05 Dec 2019

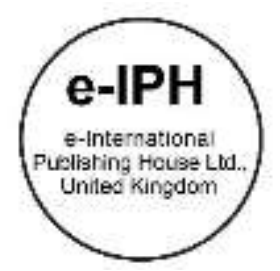

\section{Opinion of Young People on the Crises of Emerging Adulthood: Premarital Sex, Ex-nuptial Pregnancy and Infant Abandonment}

\author{
Salmi Razali 1,2, Suzanna Daud 1,2, Bahiyah Abdullah 1,2, Farnaza Ariffin 1,2 \\ ${ }^{1}$ Faculty of Medicine, Universiti Teknologi MARA, Sungai Buloh, 47000 Selangor, Malaysia \\ 2Maternofetal \& Embryo Research Group (MatE), Faculty of Medicine, Universiti Teknologi MARA, \\ Sungai Buloh, 47000 Selangor, Malaysia \\ drsalmi@gmail.com, suzannadaud@hotmail.com, akakbahiyah@gmail.com, farari74@gmail.com, \\ Tel of 1st Author: +6 03-6126 5000
}

\begin{abstract}
Premarital sex, ex-nuptial pregnancy and infant abandonment are increasing problems. This study aimed to explore the opinion of youngsters on the contributing factors of this triad. A focus group discussion was conducted among 59 consented youngsters who were clustered into six groups. Standard prompts were given, discussions were audiotaped, transcribed and thematically analyzed. Main themes emerged as the contributing factors include adjustment with the transition in life, conflict in relationships and lacking internal defenses. Understanding these factors within the social development of youngsters is essential to equip them in making an informed decision on their sexuality and crises in life.
\end{abstract}

Keywords: ex-nuptial pregnancy, infant abandonment, premarital sex, youngsters

eISSN: 2398-42870 2021. The Authors. Published for AMER ABRA cE-Bs by e-International Publishing House, Ltd., UK. This is an open access article under the CC BYNC-ND license (http://creativecommons.org/licenses/by-nc-nd/4.0/). Peer-review under responsibility of AMER (Association of Malaysian Environment-Behaviour Researchers), ABRA (Association of Behavioural Researchers on Asians/Africans/Arabians) and cE-Bs (Centre for Environment-Behaviour Studies), Faculty of Architecture, Planning \& Surveying, Universiti Teknologi MARA, Malaysia.

DOI: https://doi.org/10.21834/ebpj.v6iSI4.2896

\subsection{Introduction}

Globally, the prevalence of premarital sex varies widely from one country to others. The prevalence of ever-had sex among adolescents aged 13 to 17 years in Southeast Asia ranged from 5.7 to 11.9\% (World Health Organization, 2013). In Malaysia, the prevalence of premarital sex among the young person is much lower, ranging from 2.9- 5.4\%, but predicted to be increasing (Lee, Chen, Lee, \& Kaur, 2006; Nawi, Roslan, Idris, \& Hod, 2017). Following the increase of premarital sexual activities, the rate of ex-nuptial pregnancy is also expected to rise. In Malaysia, one of the consequences of premarital sex and having ex-nuptial pregnancy is infant abandonment. Local researchers who evaluated police records indicated that the rates of illegal infant abandonment also have increased. In the last millennium, the triad of premarital sex, ex-nuptial pregnancy and infant abandonment is seldom heard, but in recent decades, the rates have fluctuated between 13.06 and 16.33 per 100,000 live birth (Razali, Kirkman, Ahmad, \& Fisher, 2014). In half of the cases, the infants or fetus were found dead, and a proportion of cases involved adolescents and youngsters as the perpetrators (Razali et al., 2014).

Possible associated factors for this social crises were taking illicit drugs, truancy, vandalism and bullying (Omar et al., 2010). Besides, reading or watching pornography and masturbation were also contributing to premarital sexual intercourse. Premarital sexual activity could lead to pregnancy among youngsters, and the majority of them were unmarried who less likely to practice safe sex nor contraception (Lee et al., 2006; Omar et al., 2010). Most of the pregnancy was unplanned and unintended (Omar et al., 2010).

eISSN: 2398-4287@ 2021. The Authors. Published for AMER ABRA CE-Bs by e-International Publishing House, Ltd., UK. This is an open access article under the CC BYNC-ND license (http://creativecommons.org/licenses/by-nc-nd/4.0/). Peer-review under responsibility of AMER (Association of Malaysian Environment-Behaviour Researchers), ABRA (Association of Behavioural Researchers on Asians/Africans/Arabians) and cE-Bs (Centre for Environment-Behaviour Studies), Faculty of Architecture, Planning \& Surveying, Universiti Teknologi MARA, Malaysia.

DOI: https://doi.org/10.21834/ebpj.v6iSI4.2896 
Youngsters who practice premarital sex were most likely to be in low socioeconomic status, had a low educational level and unemployed (Omar et al., 2010). They were likely to be raised by a single parent and exposed themselves to poor parenting, lack of father figure, inadequate supervision and financial difficulties than those living with both parents. Experiencing these difficulties during early life development may increase further their risk of having social problems, including having premarital sex and ex-nuptial pregnancy (Vikat, Rimpelä, Kosunen, \& Rimpelä, 2002). Perhaps, low academic achievements and problem in school may attract them to motherhood as an alternative (Farber, 2009).

Premarital sex among youngsters could give various adverse effects to both the mothers and their infants. For the mothers, young women who were pregnant carried 2- to 3-fold increased risk of anemia, perinatal morbidity, miscarriage and pre-eclampsia among young mothers. (WHO, 2009). Furthermore, premarital sex increased the incidence of preterm labor, low birth weight and intrauterine growth restriction (Omar et al., 2010). The triad of premarital sex, ex-nuptial pregnancy and infant abandonment also increase the tendency for youngsters to be marginalized and excluded from the society due to stigma and negative perceptions against these behaviors (Razali, Kirkman, \& Fisher, 2016). Moreover, acting in concert with violence against women (such as rape, sexual harassment and intimate partner abuse) this triad has been shown to associate with criminal behaviors including neonaticide, filicide or murder (Razali, Fisher, \& Kirkman, 2018; Razali et al., 2014; Razali et al., 2016)

Locally, despite obvious damaging consequences, studies investigating the perspective of youngsters on this triad of social crises are lacking. The voices of youngsters are seldom heard, and their opinions are rarely asked to serve as academic references neither to inform interventions. It is important for the policymaker to understand the opinions of the youngsters on factors contributing to these problems as it may generate the opportunity to inform appropriate interventions, programs or solutions suitable to this group of people. Therefore, our study aimed to explore the opinion of youngsters on contributing factors of premarital sex, ex-nuptial pregnancy and infant abandonment in Malaysia which primarily focusing on youngsters in college.

\subsection{Methodology}

2.1 Study design, samples and sampling strategy

In this qualitative study, focus group discussions (FGDs) were used for data collection. A total of 6 FGDs of nine to ten youngsters aged between 18 to 30 years and were able to communicate in Bahasa Malaysia or English were interviewed. The participants were students of three colleges who came for a community program in one suburban area in Malaysia. A purposive nonprobability approach was used to recruit the participants.

\subsubsection{Data collection}

Ten nursing graduates aged around 20 to 21 years old were trained by an expert in a qualitative study to be the moderator for the FGDs. Only participants who signed the informed consent form were invited for the discussion. At the beginning of each FGD, all participants were asked to complete a short questionnaire of their demographic details.

Semi-structured questions were developed by the research team as prompts aiming to identify possible contributing factors experienced by youngsters that may contribute to the social crises; the triad of premarital sex, ex-nuptial pregnancy and infant abandonment. The prompts were tested within and revised by the research team as well as pilot-tested in a group of ten university students before the fieldwork. During the FGDs, the moderators followed the question guide but asked side questions to obtain more indepth information about the topics and showed enough flexibility to allow open discussions between students. Each focus group was facilitated by those trained moderators and observed by the research team. Each FGD lasted between 90 and 120 minutes.

TABLE 1: Focus Group Question Guide

\begin{tabular}{|l|l|}
\hline Question Type & The Questions \\
\hline Opening & 1. What is your name? Where are you from? \\
\hline Introduction & $\begin{array}{l}\text { 2. Ask participants for examples of common social problems } \\
\text { experienced by adolescents or youngsters in this country. }\end{array}$ \\
\hline Transition & $\begin{array}{l}\text { 3. Thinking about 'premarital sex', 'ex-nuptial baby' and 'baby } \\
\text { abandonment', what comes to your mind? }\end{array}$ \\
\hline Key & $\begin{array}{l}\text { 4. Imagine that you have a friend which such problems, what } \\
\text { could be the possible contributing factors to her condition? } \\
\text { 5. If it occurs to other people, what are other factors that you } \\
\text { know might contribute to the conditions? }\end{array}$ \\
\hline Ending & 6. Do you have any last remarks about this condition? \\
\hline
\end{tabular}

\subsubsection{Data analysis}

The FGDs were audiotaped and then transcribed verbatim manually in Microsoft Word. The transcripts were read iteratively to ensure the researchers clearly understand the data. Pseudonyms were used to ensure anonymity. All quotes were encoded using the qualitative data analysis software (QDA Miner) program. Data were analysed using inductive thematic analysis. The credibility of this study was achieved through group discussion and checking process between members of the researchers. We have planned the research with proper timeline, rigorous data analysis and record-keeping to ensure its conformability and dependability. This study has also used specific criteria for participants' selection to ensure the transferability of these research findings to other youngsters. In ensuring the 
reliability of data interpretations, doubts or disagreements were discussed with other researchers until consensus was reached. The study was approved by the Research and Ethics Committee of Universiti Teknologi MARA.

\subsection{Results}

\subsection{Background of the participants}

A total of 59 young Malay people; $44(74.6 \%)$ female and $15(25.4 \%)$ male; aged between 18 to 29 years old mean age ( \pm SD) of 21.3 $( \pm 1.8)$ joined the $6 \mathrm{FGDs}$. All of them were students in tertiary education; $51(86.4 \%)$ were in their first or second year of university study, and $8(13.6 \%)$ were in college study. Their studies were either supported by their parents $(n=29 ; 49.2 \%)$, scholarship $(n=17 ; 28.8)$ or other financial resources $(n=8 ; 13.6 \%)$. All of them were unemployed except for one who did a part-time job. All of them were single, never married. Less than half $(n=22(37.3 \%)$ were in a close relationship, and the remaining were not.

\subsection{The emergent themes}

There were three themes that emerged from the thematic analysis:

\section{Theme 1: Adjustment with the transition in life}

The participants described that lack of adjustment with the transition in life could have contributed to the phenomena. A few of the participants described the experience as a "culture shock" when they have to move from living with family in their village in rural areas to college in urban areas. Most who came from well controlled-environment; previously lived in rural area under close supervision by parents at home and teachers at school felt that there was lack of control by college authority in terms of students' social behaviours. College authority, according to most of the participants, provided a permissible environment and lenient disciplinary action for couples who showed intimacy. The result, according to them, was having ex-nuptial pregnancy and then infant abandonment. As described by one of the participants who was living in a rural area before her study,

\footnotetext{
"We came from the village (kampong), then came to the urban area to continue our education. Then, we followed the culture of those in town, left behind village culture. The culture of holding hands is uncommon when I was in my village. Now that I am in the hostel, that behaviour (holding hands between the couple) is too bad. It is a culture shock for me! The guard (in the campus) did nothing. When sitting together, of course, we want to do sex. So when you get pregnant, then the easy way is to dump the baby". Translated, Mala, 23
}

\section{Theme 2: Conflict in relationships}

The participant described two meaningful relationships which strongly influenced how youngsters adjust with the transition in life; i) Peers relationship and ii) Parents and Family relationships. The pattern of friends or peers relationships, according to them, can be divided further into two patterns of relationships. These types of relationships that may increase the tendency for premarital sex and subsequently ended up with having ex-nuptial pregnancy; romantic relationship vs isolation

Many of the participants suggested that the main factor for having ex-nuptial pregnancy is because of youngsters started to have a romantic relationship. The trajectory to premarital sex in the context of college students described by the participants began when the students felt pressured to conform to the college culture that most college students should have a special partner. One of the girls suggested that students without a special partner would feel ostracised from others. At the same time, they felt compelled to abide by the religious belief and social perception that having a romantic relationship out-of-wedlock is forbidden and transgressive. As a result, youngsters would find (non)permissible ways to maintain the relationship. One of the students described the situation in details,

\footnotetext{
"Romantic relationship begins with (two youngsters) being as a couple. Initially, (they) were sending messages at night without parents' knowledge. Despite the fact that parents have reminded (them) of not to be a couple (having a romantic relationship) since such behaviour is forbidden, the youngsters kept going out at night. They were telling lies; instead of going out with a female friend, (she) went out with a male friend. Lastly, it ended up with (premarital sex and then having ex-nuptial pregnancy)". Translated, Anna, 21
}

Other participant described further that the pathway then continued with the behaviour of holding hands, then patting, which often occurred in secluded areas such as dark places, a park, inside the car or bus. A few of the participants believed that young women and girls easily got obsessed with her partner. To convince the partner that she loves him, she would consent to the sexual relationship. To prevent such a situation, many of the participants believed that going out in a group, instead of just together as a couple, perhaps can limit the premarital sexual activities. They also suggested that it is appropriate to have many friends in the opposite gender but limit to just casual friendship or non-romantic relationship.

The other type of relationship described by the participants was related to those who tend to be socially isolated. According to the participants, instead of having a relationship with other colleagues, this type of youngsters preferred to occupy their time alone and spend time browsing the internet and using their mobile phone. They described further that this type of youngsters has the tendency to watch pornography. When their sex drive was uncontrollable, they might involve in a non-consensual sexual relationship, sexual assault or rape.

Many participants described the crucial role of the relationship between family, parents and youngsters. In details, they described lack of bonding between parents and youngsters, lack of warmth and love from the parents and family, poor parenting and poor discipline at home could predispose youngsters to premarital sex and eventually involve in infant abandonment. The participants suggested two 
types of parenting; i) receptive parents who understand the challenges faced by youngsters. Youngsters would be comfortable to share their problems (including having ex-nuptial pregnancy) with this type of parents. In contrary, according to the participants, there are ii) parents who are very harsh and punitive, making it difficult for youngsters to disclose and share their problem with them. One of the participants explained,

"There are two types of parents. Some are open-minded and those who could not accept the facts; this is the dangerous one! If you suddenly tell them about having ex-nuptial pregnancy, you can die because of being punished by this type of parents!" Translated, Alin, 22

\title{
Theme 3: Lacking internal defences
}

Another factor that suggested by the majority of the participants contributed to premarital sex, ex-nuptial pregnancy and infant abandonment was lacking internal defences in particular in two areas: i) religious adherence, and ii) psychological skills. They believed that not only lack of knowledge, but most important was lack of religious practice would contribute to the phenomena. One of the participants described that,

\begin{abstract}
"Perhaps the main factor is the religious factor. We cannot blame our parents. Parents have provided us with enough religious knowledge. Perhaps, it is our own fault....we have the knowledge, but we don't want (to practice). We follow other people's behaviour. We do things which are beyond the (religious) boundaries". Translated, Zainab, 20
\end{abstract}

Apart from religion, the participants suggested the importance of psychological elements. They suggested that the phenomena occurred as a result of a lack of self-efficacy and self-determination to control their own behaviour. She suggested that,

This matter relies on ourselves. Despite how high is your religious practice, and whether you socialise with good friends or not, we should know how to look after ourselves. It depends on ourselves. We should be internally strong to avoid such matters.

Translated, Syura, 21

\subsection{Discussion}

Experts in the science of human development understood that between 18-23 years of life, youngsters are in crises to adjust with the normal developmental transformation of "emerging adulthood" (Gilmore \& Meersand, 2019). They are struggling to change from obedient childhood to the arena of autonomy, sexuality, self-identity, self- determined values and career pathways (Gilmore \& Meersand, 2019). In this study, the youngsters described during this phase of development those who practice premarital sex or sex out-of-wedlock are in crises to choose between fulfilling internal (their sexuality needs) and conforming to external (college culture, societal religious and moral values). Internally, it is well known that during this stage, the great challenge for the youngsters is the spurts of sex hormones. The needs for deep emotional connections and intimacy, as well as the increase in libidinal impulses, are parts of the challenges (Willoughby, 2012).

Moreover, adjustment to new sociocultural and environment of college is another crucial factor. These crucial elements include lack of supervision, inadequate monitoring and poor disciplinary action from campus authority. At the earlier stages of development, parents and teachers have taken the responsibility to ensure continuous control. However, minimum control received while in college, hence youngsters have more freedom to express and practice their chosen sexual and social behaviours. In a review study that examined the behaviour of "hooking up" among college students, similar findings were found. The authors of the review argued that shifts in the pattern of intimacy throughout the $20^{\text {th }}$ century occurred as a result of the culture of parents being the "gatekeeper" has faded, and peers' oversight has strengthened (Stinson, 2010).

While striving to find balance during the transition in life, youngsters in this study described the crucial element of having stable relationships from both parents and family, as well as friends. Those who ended up with having premarital sex, ex-nuptial pregnancy and then have a tendency for abandoning their baby are those who experienced conflict in these two relationships. They received a lack of family support and inadequate guidance from their parents and family. The participants described lack of parent-child bonding, lack of warmth and love from the parents and family, poor parenting and poor discipline at home might put youngsters at risk for premarital sex and eventually involve in infant abandonment. Other local researchers have also described the importance of parents and family in providing positive elements for their children (Razali et al., 2016).

Moreover, parents and family should also play an active role in supporting teachers at school and sharing knowledge with their children on sexuality education (Khalaf, Low, Merghati-Khoei, \& Ghorbani, 2014). Elsewhere, researchers suggested that other vital elements such as attitudes of the parents regarding adolescent sexuality; the marital and childbearing behaviour of parents (such as perceptions on out-of-wedlock pregnancies, educational background, work patterns, and communication (Shabrina \& Nursasi, 2018). Researchers also believed that the pattern of attachment between parents and their children could influence the sexual behaviours of youngsters. Those with insecure attachment may have more of hooking up behaviours than those with secure attachment (Stinson, 2010). Without strong quality in the parent-child relationship, youngsters would be more attracted to their peers and close friends. Peers influence a lot of youngsters' perspective towards the sexual relationship. If the peers are those who practice courtship and intimate relationship with their partners, youngsters will tend to follow (Behulu, Anteneh, \& Aynalem, 2019).

Another pivotal element for the adjustment during this emerging adulthood period is the strength of internal defences. The two elements were religious adherence and psychological skills. Lack of adherence to religious practice may predispose youngsters to actively engage in premarital sexual activities; transgressing the teaching of religion (Islam) that forbid free social and sexual relationships with 'non-mahram' or unmarriageable kin. Such behaviours were believed to eventually increase their tendency for having 
an ex-nuptial infant and infant abandonment. The importance of religiousness concerning these phenomena has been described by other local researchers (Awaluddin et al., 2015). Other studies among youngsters of other religions have also shown that the level of religiousness determines sexual behaviour (Lefkowitz, Gillen, Shearer, \& Boone, 2004).

The other crucial internal defence, according to youngsters in this study were psychological skills such as self-efficacy and selfcontrol. Local experts also suggested similar attributes in addition to other psychological skills such as problem-solving skills, assertiveness and coping skills (Razali, Daud, \& Bahiyah, 2017) Moreover, according to the literature, in addition to embracing religion and having strong psychological skills is the level of knowledge on sexuality (Khalaf et al., 2014). In this study, however, the participants did not highlight this element as an important contributor to the phenomena. Perhaps, in Malaysia, sexuality education is integrated only in the primary and secondary school curriculum, and no emphasis is given to incorporate this element in the syllabus of tertiary education (Khalaf et al., 2014; Razali, Ramli, et al., 2017)

\subsection{Conclusion and Recommendations}

Premarital sex, ex-nuptial pregnancy and infant abandonment are alarming social phenomena among emerging adults in Malaysia. It is crucial to understand the opinion of the youngsters on the contributing factors of this triad directly from themselves in order to address the root causes and to prevent this from happening expediently; hence more studies are required. The emphasis also should be given to ensure young generation are responsible and well informed to choose the best way for a healthy relationship and well-adjusted with the transition in life so that social crises such as premarital sex, having ex-nuptial pregnancy and infant abandonment could be prevented. Empowering positive psychological skills, adherence to religious practice, enhancing sexuality and reproductive knowledge as well as embracing a healthy parent-child relationship should be the fundamental strategies to address these phenomena.

\section{Acknowledgement}

The authors gratefully acknowledge the help of the Universiti Teknologi MARA in providing the grant 600-IRMI/MYRA 5/3/LESTARI (0128/2016) which partially funded this project and the Faculty of Medicine, Universiti Teknologi MARA for assisting in the community project and the presentation of this paper in the conference. The authors also would like to acknowledge Mrs Fatimah Sham, Mr Razif Dasiman and Professor Dr Nor AShikin Mohamed Noor Khan, who contributed to data collection and the transcribing process.

\section{References}

Awaluddin, S. M., Ahmad, N. A., Saleh, N. M., Aris, T., Kasim, N. M., Sapri, N. A. M., \& Rashid, N. (2015). Prevalence of sexual activity in older Malaysian adolescents and associated factors. Journal of Public Health Aspects, 2(1), 1.

Behulu, G. K., Anteneh, K. T., \& Aynalem, G. L. (2019). Premarital sexual intercourse and associated factors among adolescent students in Debre-Markos town secondary and preparatory schools, north-west Ethiopia, 2017. BMC research notes, 12(1), 95.

Farber, N. (2009). Adolescent pregnancy: Policy and prevention services: Springer Publishing Company.

Gilmore, K., \& Meersand, P. (2019). Normal child and adolescent development. In L. W. Roberts (Ed.), Textbook of Psychiatry (pp. 76): The American Psychiatric Association Publishing.

Khalaf, Z. F., Low, W. Y., Merghati-Khoei, E., \& Ghorbani, B. (2014). Sexuality education in Malaysia: Perceived issues and barriers by professionals. Asia Pacific Journal of Public Health, 26(4), 358-366.

Lee, L. K., Chen, P., Lee, K., \& Kaur, J. (2006). Premarital sexual intercourse among adolescents in Malaysia: a cross-sectional Malaysian school survey. Singapore medical journal, $47(6), 476$.

Lefkowitz, E. S., Gillen, M. M., Shearer, C. L., \& Boone, T. L. (2004). Religiosity, sexual behaviours, and sexual attitudes during emerging adulthood. Journal of sex research, 41(2), 150-159.

Nawi, A. M., Roslan, D., Idris, I. B., \& Hod, R. (2017). Bullying and truancy: predictors to sexual practices among school-going adolescents in Malaysia-a cross-sectional study. Med J Malaysia, 72(5), 298-305.

Omar, K., Hasim, S., Muhammad, N. A., Jaffar, A., Hashim, S. M., \& Siraj, H. H. (2010). Adolescent pregnancy outcomes and risk factors in Malaysia. International Journal of Gynecology \& Obstetrics, 111(3), 220-223.

Razali, S., Daud, S., \& Bahiyah, A. (2017). Peace for Women; Modul Kesejahteran Minda dan Kesihatan Wanita. Selangor, Malaysia: Amirsa Enterprise.

Razali, S., Fisher, J., \& Kirkman, M. (2018). "Nobody came to help": interviews with women convicted of filicide in Malaysia. Archives of women's mental health, 1-8.

Razali, S., Kirkman, M., Ahmad, S. H., \& Fisher, J. (2014). Infanticide and illegal infant abandonment in Malaysia. Child abuse \& neglect, 38(10), 1715-1724.

Razali, S., Kirkman, M., \& Fisher, J. (2016). Overlaps and Gaps in Understanding Filicide in Malaysia: Framework Analysis of the Perspectives of Service Providers and Convicted Women. Paper presented at the International Conference on Women and Children Legal and Social Issues, Malaysia. 
Razali, S., Ramli, N. A. F., Hanafia, S. S., Rahman, N. N. A., Md, K. N., Rani, M. A. M., ... Ariffin, A. F. (2017). Are Malaysians ready for comprehensive sexuality education? Journal of Advanced Research in Social and Behavioural Sciences, 9(1), 14-28.

Shabrina, C. H., \& Nursasi, A. Y. (2018). Correlation between parent-adolescent communication and adolescents' premarital sex risk. Enfermeria clinica, 28, 51-54.

Stinson, R. D. (2010). Hooking up in young adulthood: A review of factors influencing the sexual behaviour of college students. Journal of College Student Psychotherapy, 24(2), 98-115.

Vikat, A., Rimpelä, A., Kosunen, E., \& Rimpelä, M. (2002). Sociodemographic differences in the occurrence of teenage pregnancies in Finland in 1987-1998: a follow up study. Journal of Epidemiology \& Community Health, 56(9), 659-668.

Willoughby, B. J. (2012). Associations between sexual behaviour, sexual attitudes, and marital horizons during emerging adulthood. Journal of Adult Development, 19(2), $100-110$

World Health Organization. (2013). Accessed December 11. (2013). Global School-based Student Health Survey. Cambodia: 2013 fact sheet. . http://www.who.int/chp/gshs/2013_Cambodia_GSHS_Fact_Sheet.pdf. . 